\title{
PROMOÇÃO DA SAÚDE A PARTIR DA APRENDIZAGEM POR PROJETOS
}

\section{HEALTH PROMOTION THROUGH PROJECT-BASED LEARNING}

\author{
ILHA, Phillip Vilanova \\ phillip_ilha@hotmail.com \\ UFSM - Universidade Federal de Santa Maria \\ LIMA, Ana Paula Santos \\ ana_paula.sm@hotmail.com \\ UFSM - Universidade Federal de Santa Maria \\ VISINTAINER, Daniela Sastre Rossi \\ danisrossi@gmail.com \\ UFSM - Universidade Federal de Santa Maria \\ WOLLMANN, Ediane Machado \\ edianewollmann@gmail.com \\ UFSM - Universidade Federal de Santa Maria \\ SOARES, Félix Alexandre Antunes \\ felix@ufsm.br \\ UFSM - Universidade Federal de Santa Maria
}

\begin{abstract}
RESUMO Este estudo verificou as percepções de professores e alunos quanto ao desenvolvimento da promoção da saúde, a partir da aprendizagem por projetos. Caracteriza-se como um estudo de caso cujo enfoque é predominantemente qualitativo. Os dados evidenciaram que os projetos tiveram dois enfoques metodológicos. No primeiro, o aluno construiu o conhecimento de forma colaborativa e o professor mediou o aprendizado, neste enfoque, deu-se maior motivação dos escolares para modificarem hábitos promotores de saúde. No segundo, o professor foi mentor das atividades e o aluno receptor, nesta metodologia, a percepção de motivação e aprendizado foi menor. Portanto, o desenvolvimento da promoção da saúde, a partir da aprendizagem por projetos, com participação ativa dos educandos na construção do conhecimento, pode trazer resultados satisfatórios quanto à melhoria da qualidade de vida dos escolares.
\end{abstract}

PALAVRAS-CHAVE: Aprendizagem por projetos. Ensino fundamental. Promoção da saúde.

ABSTRACT This study aims to assess teachers and students' perceptions on health promotion through project-based learning. For that, methodology used was case study, focused on project-based learning, by means of a qualitative method of data analysis. Thus, we have found, at first, that students have their health habits improved, and occasionally modified, when they have the opportunity of work jointly with their teachers performing as mediator. Secondly, when students do not take part 
actively on their learning and teachers behave as a leader and not as a supporter or encourager, students' perceptions and learning were significantly lower. Summing up, students' active participation on their own knowledge construction, by means of project-based learning, proved to be the most effective way to improve their health habits and life.

KEYWORDS: Elementary school. Health promotion. Project-based learning.

\section{INTRODUÇÃO}

A expressão "saúde na escola" vem sendo utilizada para designar o campo que compreende concepções, diretrizes, programas, projetos e ações relacionados à saúde que acontecem no cenário da escola, sejam de natureza educativa, preventiva ou assistencial (VALADÃO, 2004). Nesse campo, a promoção da saúde na escola corresponde a uma visão e a um conjunto de estratégias que têm como objetivo produzir repercussões positivas sobre a qualidade de vida e os determinantes da saúde dos membros da comunidade escolar.

A qualidade de vida entendida, segundo WHO (1997, p.1, tradução do autor), "como a percepção do indivíduo de sua posição na vida no contexto da cultura e sistema de valores nos quais ele vive e em relação aos seus objetivos, expectativas, padrões e preocupações", torna-se uma área multidisciplinar de conhecimento que engloba além de diversas formas de ciência e conhecimento popular, conceitos que permeiam a vida das pessoas.

Neste sentido, a escola torna-se um espaço privilegiado para influenciar e orientar as atitudes e valores dos estudantes ao longo de toda a sua escolaridade, bem como para conscientizá-los à adoção de hábitos que permitam uma melhor qualidade de vida. Aprender comportamentos promotores da saúde na escola requer que os alunos adquiram conhecimentos que Ihes permitam por em prática aquilo que aprenderam (PEREIRA, 2000).

No ambiente escolar, a promoção da saúde precisa ser compreendida como a combinação de apoios educacional e ambiental que vise à formação de atitudes e valores que levem o escolar ao comportamento autônomo, beneficiando sua saúde e aqueles que estão a sua volta (ASSIS et al., 2010). 
Temas sobre promoção da saúde não devem se limitar a dar conhecimentos, mas motivar o aprendizado, estimular o aluno a analisar e a avaliar as fontes de informações e torná-lo capaz de adotar práticas comportamentais com base no conhecimento. Tal posicionamento entende a educação como um processo que trata o conhecimento como algo que é construído e apropriado, e não como algo a ser transmitido. Conhecimento, por sua vez, é fruto da interação e cooperação entre sujeitos diferentes, os quais trazem experiências, interesses, desejos, motivações, valores e crenças únicas, singulares, mas que são, ao mesmo tempo, plurais e, por isso, diversos.

Os documentos legais publicados, no Brasil, no tocante à Educação Básica $\left(\mathrm{LDB}^{1}, \mathrm{PCNEM}^{2}, \mathrm{PCN}^{3}{ }^{3}\right.$ e OCEM $\left.{ }^{4}\right)$, enfatizam a necessidade de se promover um ensino interdisciplinar e contextualizado, com isso, objetivando mobilizar o desenvolvimento de habilidades e competências no aluno, bem como a construção da cidadania, da sua autonomia e do pensamento crítico frente à realidade. Seguindo determinações da Lei de Diretrizes e Bases da Educação Nacional (BRASIL, 1996), no que diz respeito ao papel do professor em dinamizar as aulas para despertar o interesse dos alunos pelo estudo, diferentes alternativas de ensino estão sendo implementadas pelas escolas. Estas, por sua vez, sugerem ao professor formas para diversificar o processo de ensino, assim, favorecendo o envolvimento e a aprendizagem dos alunos.

Tais documentos sinalizam que o uso de projetos no ambiente escolar, enquanto proposta pedagógica, privilegia a pesquisa no processo ensinoaprendizagem e pode se constituir em uma das estratégias que propiciam contribuir para a melhoria na qualidade do ensino e do conhecimento dos alunos. Como ressaltam as Orientações Curriculares para o Ensino Médio, o trabalho com projetos pedagógicos, além de consolidar a aprendizagem, contribui para a formação de hábitos e atitudes e para a aquisição de princípios e conceitos que podem ser generalizados para situações alheias à vida escolar (BRASIL, 2006).

\footnotetext{
Lei de Diretrizes e Bases da Educação Nacional (BRASIL, 1996)

Parâmetros Curriculares Nacionais para o Ensino Médio (BRASIL, 2000)

Orientações educacionais Complementares aos Parâmetros Curriculares Nacionais (BRASIL, 2002)

Orientações Curriculares Nacionais para o Ensino Médio (BRASIL, 2006)
} 
O método de projetos tornou-se corrente no Brasil, a partir da divulgação do movimento conhecido como Escola Nova, contrapondo-se aos princípios e métodos da escola tradicional. Esse movimento foi fruto das pesquisas de grandes educadores, entre eles, John Dewey e seu discípulo, William Kilpatrick, criadores do método de projetos. Suas propostas pedagógicas foram introduzidas e disseminadas no Brasil, principalmente por Anísio Teixeira e Lourenço Filho (AMARAL, 2003).

Reinterpretado, esse movimento tem fornecido subsídios à pedagogia dinâmica, centrada na criatividade e na atividade discentes, sob uma perspectiva de construção do conhecimento pelos alunos, mais do que na transmissão dos conhecimentos pelo professor. O método de projetos de Dewey e Kilpatrick, considerado então um método, passa agora a ser visto mais como uma postura pedagógica. Além de uma técnica atraente para transmissão dos conteúdos, como muitos pensam, tem sido proposto como uma mudança na maneira de pensar e repensar a escola e o currículo, a prática pedagógica (AMARAL, 2003).

Atualmente, há uma diversidade de concepções sobre projetos, desde as diferentes áreas do conhecimento até as diversas maneiras de seu uso na educação. As diferenças entre tais concepções apresentam-se quanto às especificidades que cada autor utilizou para adaptá-las a sua realidade, como Hernández e Ventura (1998), que priorizam a relação do currículo com os projetos de trabalhos, mas que não deixam de contemplar os princípios da prática de projetos; Behrens (2006) e Rojo (1997) enfatizam o enfoque globalizador, dentro das especificidades de cada proposta; Araújo (2003) evidencia o ensino transversal, a aprendizagem com projetos como estratégia pedagógica; Moura e Barbosa (2009) relacionam a prática de projetos como caminhos para a mudança nas organizações humanas.

Diante dessas diferentes concepções, há uma similaridade entre as discussões dos autores quando concebem a aprendizagem com projetos como um método aberto, centrado em problematizações a partir das quais os sujeitos criam oportunidades de participação ativa em processos investigativos para efeito de construção do conhecimento. As especificidades ou enfoques das concepções sobre aprendizagem por projetos representam a diversidade pedagógica que esta prática pode proporcionar, dessa maneira, ampliando as possibilidades de estratégias na 
construção do conhecimento nos diferentes componentes curriculares. Assim, não existe um modelo padrão a ser seguido, mas princípios que legitimam uma perspectiva globalizadora, que pode ser construída no decorrer do fazer pedagógico.

Neste sentido, a aprendizagem por projetos passa a ser vista como um processo complexo e global, não desassociando a teoria da prática cujo conhecimento da realidade e a intervenção nesta tornam-se faces de uma mesma moeda. E, sob tal perspectiva, dá-se maior interação entre professor e aluno porque se constrói um universo de ações diversificadas que permitem a participação ativa dos estudantes. O ponto de partida é desencadeado pelo problema que surge e conduz a investigação, busca de informações, construção de novos conceitos e seleção de procedimentos adequados. Ademais, assim percebidos, constituem atividades desenvolvidas em equipe, almejando a compreensão de uma situação, fato ou conhecimento (MELLO; DALLAN; GRELLET, 2004).

A partir dessas considerações, o presente estudo teve como problema de pesquisa a seguinte questão: Qual a contribuição de uma proposta de aprendizagem por projetos para o ensino e aprendizagem de temas relacionados à promoção da saúde?

Considerando a importância de desenvolver novas estratégias de ensino que influenciem de maneira decisiva o desenvolvimento da promoção da saúde, o presente estudo teve como objetivo verificar as percepções dos professores e alunos sobre o desenvolvimento da promoção da saúde a partir de uma proposta de aprendizagem por projetos.

\section{METODOLOGIA}

O presente trabalho foi realizado em uma escola pública estadual do estado do Rio Grande do Sul. Foram sujeitos do estudo sete professores e 56 alunos do $7^{\circ}$ ano do ensino fundamental, que assumiram o compromisso de participação espontânea no projeto.

A pesquisa caracterizou-se como qualitativa, tratando-se de um estudo de caso. Tal metodologia, segundo Yin (2001), procura conhecer uma situação complexa, suas variáveis e as inter-relações existentes no contexto analisado. Neste 
ponto, segundo o autor, o estudo de caso possibilita o aprofundamento do objeto da pesquisa, demandando um trabalho bastante rigoroso e exaustivo, de modo que o pesquisador desenvolva certas habilidades na coleta dos dados, possuindo uma versatilidade metodológica para garantir a qualidade da pesquisa.

O estudo foi aprovado pelo Comitê de Ética sob o nº. 23081.004120/2011-90; e todos os participantes ou responsáveis assinaram o termo de consentimento livre e esclarecido, conforme a Res. 196/96 do CNS.

\subsection{O CONTEXTO DO ESTUDO DE CASO}

Inicialmente, os professores passaram por uma formação continuada de seis meses, a qual visou, por meio da formação crítica e reflexiva, discutir temas relacionados à saúde e às práticas pedagógicas. Utilizou-se da seguinte sequência metodológica:

1) análise e reflexões do contexto escolar: consistiu em reflexões e discussões sobre as problemáticas encontradas no ambiente escolar e, devido ao alto grau de obesidade e maus hábitos alimentares dos alunos, elencou-se o tema Promoção da Saúde como tópico norteador da formação;

2) ciclos de estudos: constituíram-se em momentos de aprofundamentos teóricos sobre temas relacionados à promoção da saúde e estratégias metodológicas de ensino, com ênfase ao estudo da aprendizagem por projetos;

3) elaboração de projetos pedagógicos: incidiu na formulação de ações que poderiam transformar a realidade ou procurar soluções para os problemas encontrados no contexto dos alunos por meio de elaboração de projetos.

O estudo de caso foi delimitado na aplicação de uma proposta de aprendizagem por projetos para o $7^{\circ}$ ano do ensino fundamental. Este ano escolar foi selecionado por constituir-se no único que todos os professores, participantes do estudo, tinham docência.

\subsection{GRUPOS DE APLICAÇÃO DA PROPOSTA}

Para a aplicação da proposta de aprendizagem por projetos foram criados três grupos, constituídos por: 


\section{Grupo A:}

Composto por uma turma de vinte e quatro alunos (10 meninos e 14 meninas) e por dois docentes responsáveis: professor A (área das Linguagens, com 36 anos de idade, 8 anos de magistério, 20 horas/semanais de serviço e especialização na área) e professor B (área das Linguagens, com 40 anos de idade, 15 anos de magistério, 40 horas/semanais de serviço e com especialização na área).

\section{Grupo B:}

Constituído por dezessete alunos (10 meninos e 7 meninas) e por três docentes responsáveis: professor $C$ (área das Linguagens, com 39 anos de idade, 8 anos de magistério e 40 horas/semanais de serviço), professor D (área das Ciências Humanas, com 45 anos de idade, 15 anos de magistério, 40 horas/semanais de serviço e com especialização na área) e professor $E$ (área das Ciências Humanas, com 39 anos de idade, 8 anos de magistério e 55 horas/semanais de serviço).

\section{Grupo C:}

Formado por quinze alunos (7 meninos e 8 meninas) e por dois docentes responsáveis: professor $\mathrm{F}$ (área das Ciências da Natureza, com 36 anos de idade, com 9 anos de magistério, 40 horas/semanais de serviço e mestrado na área) e professor G (área da Matemática, com 25 anos de idade, 3 anos de magistério, 40 horas/semanais de serviço e especialização na área)

Todos os docentes tinham carga horária semelhante nas turmas e reuniamse a cada quinze dias para planejamento coletivo.

\subsection{INSTRUMENTOS DE COLETA DE DADOS}

Para constatar as percepções dos professores, utilizou-se uma entrevista semiestruturada, diário de campo e observação participante. A entrevista foi constituída por questões atinentes às estratégias pedagógicas utilizadas e às dificuldades encontradas na implementação da proposta. No diário de campo, foram registrados os momentos observados, com uma descrição dos sujeitos, espaços, acontecimentos e conversas, bem como as reflexões e ideias dos participantes da 
pesquisa. Os registros foram realizados em forma de descrição real, ou seja, grafados da maneira como foram ouvidos e observados e da mesma forma como nossos participantes os expuseram. Já a observação participante ocorreu pelo registro das observações e interpretações do pesquisador sobre os observados, suas ideias, reflexões e conversas.

Para a coleta de dados dos alunos, utilizou-se um questionário com questões abertas e fechadas. A primeira questão verificou a opinião dos alunos sobre as aulas dos professores, sendo composta por cinco opções de múltipla escolha: gostei mais dessas aulas; consegui aprender/entender melhor com essas aulas; achei igual às outras aulas; prefiro as outras aulas expositivas; e, não consegui aprender/entender com as aulas diferenciadas. Na segunda questão, tentou-se constatar se essas aulas estimularam os escolares a mudarem seus comportamentos em relação a sua saúde, utilizando-se da escala Likert $^{5}$ de quatro pontos. Já no terceiro questionamento, procurou-se averiguar se os conhecimentos desenvolvidos nos projetos tiveram significado e sentido para a vida dos alunos, ou seja, se os escolares conseguiram estabelecer significado ou aplicar os conhecimentos construídos nos projetos de aprendizagem em situações de vida.

\subsection{PROCEDIMENTOS DE ANÁLISE DOS DADOS}

Para analisar as entrevistas e as questões abertas do questionário, utilizouse, como principal aporte metodológico, a análise de conteúdo proposta por Bardin (2011). A análise de conteúdo foi fundamentada na análise categorial, com desmembramento das transcrições das respostas em categorias, constituída por temas que emergiam das mesmas. As respostas passaram por um crivo de classificação e de quantificação, segundo a frequência de presença ou ausência de itens de sentido. Já, nas demais questões do questionário, empregou-se a estatística descritiva (frequências e percentuais) e o teste do qui-quadrado de Pearson, com nível de significância de 5\%.

\footnotetext{
${ }^{5}$ Escala Likert é um tipo de escala de resposta psicométrica usada habitualmente em questionários. Nela pede-se ao respondente que avalie um fenômeno em um escala de opinião, utilizando opções de respostas que variam de um extremo a outro: motivou muito, motivou um pouco, motivou muito pouco, não motivaram.
} 


\section{RESULTADOS E DISCUSSÕES}

Através das análises dos dados, observou-se que o desenvolvimento das propostas de aprendizagem por projetos teve dois enfoques metodológicos, os quais são denominamos, assim como em Fagundes, Sato e Maçada (1999), de projetos de aprendizagem e projetos de ensino.

Segundo Fagundes, Sato e Maçada (1999), embora os projetos de ensino e projetos de aprendizagem tenham como características comuns o esforço de envolver o aluno na sua aprendizagem, de trazer o mundo para dentro da sala de aula ou de levá-lo a aprender sobre o mundo além dos muros da escola, eles possuem metodologias diferentes. No projeto de ensino, o professor possui a coordenação pedagógica do projeto, ou seja, o docente é mentor das atividades; e o discente, receptor, apesar de o aluno participar de forma ativa nas atividades, pesquisando, refletindo e discutindo com seus pares, é o professor que conduz as atividades em direção do que é esperado. Já no projeto de aprendizagem, o aluno constrói o conhecimento de forma colaborativa, o professor age como mediador da aprendizagem, sendo que as dúvidas, certezas e interesses dos estudantes irão gerar o próprio projeto. O ponto de partida é uma situação problemática, trazida pelos alunos ou proposta pelo professor, cujo enfrentamento vai requerer a organização de atividades de aprendizagem, que os alunos ajudam a planejar (MELLO; DALLAN; GRELLET, 2004; FAGUNDES; SATO; MAÇADA, 1999; HERNANDEZ; VENTURA, 1998).

Dos sete professores que fizeram parte da amostra, dois professores desenvolveram a proposta por projetos de aprendizagem, para o Grupo A, e cinco professores desenvolveram a proposta por projetos de ensino, para os Grupos B e C.

Para melhor referir os dados obtidos, apresentaremos primeiramente os resultados das percepções dos professores sobre o desenvolvimento da proposta e, na sequência, as percepções dos alunos.

\subsection{PERCEPÇÕES DOS PROFESSORES}


Com base na entrevista, diário de campo e observação participante, constatou-se que o desenvolvimento da proposta, para o Grupo A, seguiu o seguinte procedimento metodológico:

a) definição do tema e conhecimentos prévios dos alunos. Inicialmente, os professores indicaram parâmetros que serviram como base para que os escolares definissem a temática norteadora do projeto. $\mathrm{Na}$ sequência, os escolares expressaram suas certezas, incertezas, crenças, conhecimentos e questões sobre o tema escolhido; e os professores tiveram o papel de mediador das reflexões, confrontando as opiniões e efetuando trocas de experiências entre o grupo, assim, provocando, ao final das reflexões, o questionamento principal e norteador do projeto: Quais são as atividades físicas e de lazer praticadas pela nossa comunidade? Como se pode observar nos extratos retirados da entrevista e do diário de campo:

"[...] para introduzirmos a assunto do projeto, primeiramente colocamos um vídeo sobre atividade física [...]" (Professor B).

"[...] os alunos perceberam que não há local para praticar atividade física perto comunidade, não tem quadra, praça, apenas uma pista de caminhada ao lado da estrada, que passa muitos carros [...]" (Professor A).

"Em reunião [...] as professoras do Grupo A relataram que para a definição da temática do projeto utilizaram um vídeo introdutório. Após o filme os alunos discutiram sobre o mesmo e também sobre problemáticas relacionadas com a promoção da saúde [...] depois as reflexões, surgiu o questionamento norteador do projeto: Quais são as atividades físicas e de lazer praticado pela nossa comunidade?" (Diário de campo).

b) sistematização das atividades e pesquisa. Com o intuito de responder ao questionamento norteador do projeto, os alunos sugeriram a construção de um questionário a ser aplicado na comunidade. Para tanto, os professores planejaram e desenvolveram atividades interdisciplinares (pesquisas na sala de informática, biblioteca e fora do contexto escolar), confrontando os conhecimentos prévios dos alunos com outras visões e conhecimentos, analisando-as e relacionando-as com os 
conteúdos específicos de cada disciplina, como demonstrado nos relatos dos professores:

"[...] surgiu a ideia de realizar uma pesquisa na comunidade para verificar quais eram as atividades físicas praticadas pelas pessoas da comunidade e $o$ local onde elas praticavam" (Professora A).

"[...] planejamos as atividades que iríamos desenvolver juntas. Os alunos tinham muitas dúvidas, como iriam elaborar as perguntas, quais perguntas." (Professora B).

"[...] realizamos atividades de pesquisa na sala de informática, na biblioteca e até mesmo fora da escola. Sempre procurando relacionar com os conteúdos da disciplina com o projeto" (Professora A).

c) produção do conhecimento. Após o processo de estudos e pesquisas, levando-se em conta os conhecimentos adquiridos, os alunos confeccionaram, em pequenos grupos, a elaboração de questões referentes ao tema do projeto para serem debatidas. Para selecionar as questões que iriam compor o questionário, os professores mediaram um debate e, após, realizou-se a votação das questões mais relevantes, como se observa no relato que segue:

"[...] para escolher quais perguntas iriam fazer parte do questionário, foi realizado uma votação na turma. Onde cada grupo de alunos apresentou suas questões e também justificou a importância delas" (Professor A).

d) culminância do projeto. Devido ao término do ano letivo, a culminância do projeto deu-se pela elaboração e impressão do questionário, a ser aplicado no próximo ano letivo, apresentado na figura a seguir:

Figura 1: Questionário desenvolvido pelo Grupo A 
Projeto desenvolvido pelas professoras

Nome do projeto: Atividades físicas e de lazer

Questionário elaborado a partir das perguntas criadas pela turma 61

1. Que atividades físicas você pratica?

2. Quantas vezes por semana você pratica atividades físicas?

3. Qual seria o lugar ideal para praticar atividades físicas no seu bairro?

4. Você pratica atividades físicas como lazer ou para saúde?

5. Quais os benefícios que as atividades físicas trazem para você e sua família?

Agradecemos pela sua atenção!!!

Fonte: Diário de classe da professora A

A partir da análise dos procedimentos metodológicos do projeto Atividade Física e Lazer (Grupo A), observou-se que os professores utilizaram como principal aporte teórico os projetos de trabalho de Hernández e Ventura (1998) e a estratégia de projetos de Araújo (2003). Como destaca Araújo (2003), nessas propostas didáticas, a articulação dos conhecimentos é objetivo fundamental porque rompe com a forma rígida de enquadrar os conteúdos. Os discentes, ao procurar estudar os diferentes aspectos de um processo, têm a possibilidade de empregar na prática aquilo que foi aprendido em sala de aula e, dessa maneira, articular os diversos saberes, assim o aluno aprende no processo de produzir, de levantar dúvidas, de pesquisar e de criar relações que incentivam novas buscas, descobertas, compreensões e reconstruções do conhecimento.

Já no desenvolvimento dos projetos do Grupo $\mathrm{B}$ e $\mathrm{C}$, observou-se que não houve uma sequência de procedimentos metodológicos para o desenvolvimento da proposta. Cada grupo de professor, levando em conta as problemáticas discutidas na formação continuada, elencou o tema a ser abordado na turma: países, comidas, consumo e a cultura para o Grupo B; e alimentação saudável e qualidade de vida para o Grupo C. Esses temas foram trabalhados de forma pontual, por meio de trabalhos, aulas específicas ou dentro de uma unidade didática e restritos ao conteúdo de cada disciplina, como se pode observar nos seguintes extratos retirados das entrevistas: 
"Trabalhei o tema quando trabalhei os alimentos e sistemas digestório, mais bem focado no conteúdo [...]" (Professor F).

"Desenvolvi temas relacionados ao contexto quando foi trabalhado sobre a economia, a questão populacional. Falamos sobre a perspectiva de vida, sexo e obesidade. A gente acaba tocando nesses assuntos. Claro que não aprofundamos tanto como deveríamos [...]" (Professor D).

"Sempre que possível dei algum texto, um vídeo ou algum filme que fala sobre [...]" (Professor C).

Quando comparados o Grupo A com os Grupos B e C, pôde-se notar que, no primeiro, os temas sobre promoção da saúde são concebidos, como denomina Araújo (2003), de "eixo vertebrador", ou seja, os conteúdos programáticos deixam de ser um fim em si mesmo e passam a fazer parte de um todo, tornando o processo ensino aprendizagem em algo real para o aluno. Nesse sentido, os temas emergentes do contexto escolar são não somente valorizados, mas formam a base do desenvolvimento educacional intelectual. Já nos Grupos B e C, os conteúdos continuam organizados em torno das disciplinas tradicionais que formam a estrutura curricular; e as temáticas sobre saúde são desenvolvidas dentro dos próprios conteúdos das disciplinas, ou seja, a finalidade da educação continua sendo o ensino dos conteúdos disciplinares tradicionais e, de diversas formas, abrem-se espaços para o desenvolvimento das temáticas do projeto. Ainda, segundo o autor, nesta última concepção, reconhece-se a importância do desenvolvimento de aprendizagem por projetos, mas seu papel permanece secundário quando comparado aos conteúdos tradicionais da escola.

Quando questionados sobre as dificuldades encontradas, os professores do Grupo A apontaram a falta de tempo para planejamento como principal limitador do desenvolvimento do projeto, como revela o relato que segue:

"Temos pouco tempo para reunião. Se tivéssemos mais tempo para planejarmos as aulas, o projeto seria bem melhor [...]" (Professor B).

Já os professores do Grupo B e C assinalaram as seguintes dificuldades no desenvolvimento da proposta de aprendizagem por projetos: 
a) integração dos conteúdos curriculares com o projeto. Os professores apontaram a dificuldade de articular os conteúdos previstos para o trimestre com os temas abordados no contexto do projeto;

b) período de avaliação dos alunos. Além da dificuldade de articular os conteúdos disciplinares, os professores apontaram que, devido ao final do ano letivo, período quando há um grande número de avaliações, não conseguiram dispor de tempo necessário para desenvolver a proposta.

Por meio das observações participantes e relatos dos professores, observouse certo automatismo das rotinas pedagógicas por parte dos professores do Grupo B e C, dificultando, assim, o desenvolvimento dos projetos propostos. Mioch (1997) justifica esta atitude quando coloca que o comodismo de certos professores pode impedi-los de pensar e reagir adequadamente diante de situações novas. As exigências do sistema de ensino não podem ser vistas pelos professores, conforme descreve Prado (2003), como camisa de força, que paralisa as ações pedagógicas e o seu processo de construção. Existem momentos em que outras estratégias pedagógicas precisam ser colocadas em ação para que os alunos possam aprender determinados conceitos, por isso, é necessário que o professor tenha abertura e flexibilidade para relativizar a sua prática e as estratégias pedagógicas com vistas a propiciar ao aluno a reconstrução do conhecimento.

Constatou-se, através do desenvolvimento das propostas de aprendizagem por projetos, que apenas dois professores (Grupo A) mudaram efetivamente suas práticas docentes. Já quanto aos demais professores (Grupo B e C), notou-se, por meio dos relatos e da observação participante, que os mesmos percebem que precisam mudar suas práticas docentes, mas não sabem bem como fazê-lo ou não se encontram preparados para experimentar uma mudança significativa com segurança, pois um dos desafios da aplicação da aprendizagem por projetos é a dificuldade de gerir o tempo, detendo-se por um longo período para atingir os objetivos educativos. Outro inconveniente está associado à dificuldade do professor em tempo útil, de conseguir orquestrar os ritmos de trabalho diferenciados dos alunos e de nem sempre ter a possibilidade de corrigir os percursos de aprendizagem de cada estudante. Aliado a isso, somam-se as exigências do sistema de ensino de cumprir o planejamento, entregar notas, cadernos, entre outras. 
Após a análise das estratégias pedagógicas utilizadas pelos docentes, verificaram-se as percepções dos professores a partir do seguinte questionamento: Você percebeu se os alunos sentiram-se motivados e se houve maior ou menor aprendizado com essas atividades quando comparados com as aulas que você normalmente ministrava?

Cinco professores (dois professores do Grupo A, um do Grupo B e dois do Grupo C) apontaram aspectos positivos, como se observa nos relatos:

"[...] a gurizada é meio complicada, no início alguns mostram mais interesses que os outros, mas aos poucos todos participaram [...] Houve aprendizado, os alunos começaram a pesquisar, refletir, conversar sobre as atividades físicas que faziam em casa e na escola e observar o que faz bem para a saúde [...]" (Professor A).

"Percebi melhora no aprendizado dos alunos. Os alunos tornaram-se mais participativos e interessados nos conteúdos. Apenas o tempo do projeto foi curto, mas satisfatório" (Professor B).

"Sim, os alunos começaram a analisar o tipo de alimentação que tinham em casa e na escola e observar o que faz bem para a saúde” (Professor F).

"Sim, porque os alunos gostam do debate e das diferenças culturais" (Professor E).

"Sim, porque se trabalhou temas de interesse deles e utilizou-se de recursos audiovisuais" (Professor G).

Os demais professores (um do Grupo B e um do Grupo C) relataram, de forma objetiva e sem justificativas, não ter percebido motivação e melhora no aprendizado dos alunos.

Constatou-se, assim, que, apesar de utilizarem metodologias diferentes, a maioria dos professores, cinco $(71,4 \%)$, percebeu maior motivação dos alunos para o aprendizado e também que novos conceitos foram agregados a respeito da sua promoção da saúde. Dessa forma, como afirma Helm e Beneke (2005), buscar, no contexto dos alunos, temas relacionados a sua própria saúde e proporcionar condições para reconstruir o seu saber a partir do conhecimento formal motiva-os a quererem conhecer mais sobre os fenômenos que vivenciam e que os instigam. 


\subsection{PERCEPÇÕES DOS ALUNOS}

Primeiramente, procurou-se averiguar qual a opinião dos alunos a respeito das aulas dos professores que desenvolveram a proposta de aprendizagem por projetos. Os resultados podem ser observados na Tabela 1.

Tabela 1: Opinião dos alunos em relação às aulas que desenvolveram a aprendizagem por projetos.

\begin{tabular}{|c|c|c|c|}
\hline Categorias & $\begin{array}{c}\text { Grupo A } \\
\mathrm{n}(\%)\end{array}$ & $\begin{array}{c}\text { Grupo B } \\
\mathrm{n}(\%)\end{array}$ & $\begin{array}{c}\text { Grupo C } \\
\mathrm{n}(\%)\end{array}$ \\
\hline Gostei mais dessas aulas & $19(79,2 \%)^{\mathrm{ab}}$ & $07(41,2 \%)$ & $05(33,3 \%)$ \\
\hline Consegui aprender melhor com essas aulas & $15(62,5 \%)^{b}$ & $06(35,3 \%)$ & $04(26,7 \%)$ \\
\hline Achei igual às outras aulas & $04(16,7 \%)$ & $04(23,5 \%)$ & $05(33,3 \%)$ \\
\hline Prefiro aulas expositivas & $01(04,2 \%)$ & $02(11,8 \%)$ & $02(13,3 \%)$ \\
\hline Não consegui aprender com estas aulas & $01(04,2 \%)$ & $03(17,6 \%)$ & $03(20,0 \%)$ \\
\hline
\end{tabular}

Observou-se que o maior percentual das opiniões dos alunos, em relação às aulas desenvolvidas com aprendizagem por projetos, concentrou-se na resposta "gostei mais dessas aulas", com maior frequência no Grupo A $(79,2 \%)$ em relação ao Grupo B e C (41,2\% e 33,3\% respectivamente).

Foi possível individuar que, os alunos do Grupo $\mathrm{A}$, além de gostarem mais das aulas, perceberam que conseguiram aprender melhor com estas. Pois, as opiniões dos mesmos apontaram que $62,5 \%$ da turma perceberam que os projetos facilitaram o aprendizado dos temas relacionados com a promoção da saúde.

Estes resultados reforçam a ideia de Nogueira (2006), o qual relata que o educando passa a interessar-se mais pela aula quando o ensino ganha significado para ele, ou seja, quando o mesmo aprende no processo de produzir, de levantar dúvidas, de pesquisar e de criar relações que incentivam novas buscas, descobertas, compreensões e reconstruções de conhecimentos. Partindo dessa premissa, o aluno se compromete e interessa-se de maneira mais profunda pela sua 
própria formação, pois terá autonomia para tomar decisões. Do ponto de vista de aprendizagem por projetos, Prado (2003) destaca a possibilidade do aluno recontextualizar aquilo que aprendeu, bem como estabelecer relações significativas entre conhecimentos, com isso, ressignificando conceitos, desenvolvendo competências e mudando comportamento.

Contudo, ao comparar as respostas dos Grupos, é possivel verificar que os Grupos B e $C$ apresentaram percentuais bem inferiores quando comparados às respostas de "gostei mais dessas aulas" do Grupo A. Com diferenças estatisticamente significativas entre os Grupos A e B $(p=0,021)$ e entre os Grupos A e $C(p=0,007)$. Observou-se também, percentuais inferiores na resposta "consegui aprender melhor com essas aulas" dos Grupos B e C em relação do Grupo A. Com diferença estatisticamente significativa entre o Grupo A e $C(p=0,048)$.

Estes resultados demonstram que, quando o professor assume o papel central do processo ensino aprendizagem, como agente transmissor do conhecimento (Grupos B e C), os alunos sentem-se menos interessados e as atividades são menos facilitadoras do aprendizado ao comparar com as aulas em que a construção do conhecimento é colaborativa entre professor e alunos (Grupo A). Hernández e Ventura (1998) colocam que "o aluno aprende (melhor) quando torna significativa a informação ou os conhecimentos que se apresentam na sala de aula", e para isso o educando não pode ser visto como mero receptor passivo de conhecimento.

Moran (2013, p. 27) salienta que há outros fatores que também influenciam na aprendizagem, como o próprio autor coloca "aprender depende, principalmente, de motivação, foco, metodologias e atitude". Haverá melhor aprendizado se houver, entre outros fatores, uma motivação para concentrar no conhecimento, caminhos metodológicos diferentes, que se ajustam melhor a cada situação ou sujeito e, se houver uma predisposição para aprender.

Nesse sentido, foi averiguado se os projetos de aprendizagem estimularam os escolares a mudarem seus hábitos em relação a sua promoção da saúde. Os resultados podem ser observados na tabela 2 . 
Tabela 2: Opiniões dos alunos sobre o questionamento "As aulas desenvolvidas por projetos estimularam você a mudar seus hábitos promotores de saúde?"

\begin{tabular}{lccc}
\hline \multicolumn{1}{c}{ Opiniões } & $\begin{array}{c}\text { Grupo } \mathrm{A}^{\mathrm{a}} \\
\mathrm{n}(\%)\end{array}$ & $\begin{array}{c}\text { Grupo B } \\
\mathrm{n}(\%)\end{array}$ & $\begin{array}{c}\text { Grupo C } \\
\mathrm{n}(\%)\end{array}$ \\
\hline Motivaram muito & $15(62,4 \%)$ & $05(29,4 \%)$ & $05(33,3 \%)$ \\
\hline Motivaram um pouco & $07(29,2 \%)$ & $07(41,2 \%)$ & $01(6,7 \%)$ \\
\hline Motivaram muito pouco & $01(04,2 \%)$ & $04(23,5 \%)$ & $06(40,0 \%)$ \\
\hline Não estimularam & $01(04,2 \%)$ & $01(5,9 \%)$ & $03(20,0 \%)$ \\
\hline${ }^{a}$ Houve diferença significativa entre os Grupos A e C (p<0,05) \\
Fonte: Elaborado pelos autores
\end{tabular}

Constatou-se que a maior proporção dos escolares do Grupo A $(62,4 \%)$ sentiu-se muito motivado em alterar seus hábitos promotores da saúde. Enquanto que, o maior percentual de escolares do Grupo B $(41,2 \%)$ sentiu-se um pouco motivado e, os educandos do Grupo C $(40,0 \%)$ sentiram-se muito pouco motivados.

Com o objetivo de determinar o relacionando entre as variáveis, verificamos a associação da percepção de motivação dos escolares entre os grupos. Constatou-se que apenas entre os Grupos A e C houve associação significativa $(p=0.026)$, ou seja, as respostas dos alunos estão relacionadas ao grupo que pertencem. Como os percentuais de percepção da motivação foram superiores no Grupo A, consta-se que estes sentiram-se mais incentivados em modificarem seus hábitos promotores de saúde quando comparados com os alunos do Grupo C.

Levando em conta, que o Grupo A desenvolveu sua proposta de aprendizagem por projetos baseado no enfoque metodológico denominado como projetos de aprendizagem e o Grupo $\mathrm{C}$ baseou-se no enfoque de projetos de ensino, estes resultados, confirmam a colocação de Nogueira (2006), o qual relata que, ao inserir projetos de aprendizagem no ambiente escolar, as aulas tornam-se mais motivadoras, pois se abrem as portas para uma prática educativa voltada para as questões do contexto dos alunos.

Salienta-se que, além de uma metodologia adequada ao contexto e características dos alunos há outros fatores que podem influenciam a aprendizagem. Ausubel, Novak e Hanesian (1980) coloca duas condições para a aprendizagem tornar-se significativa: 1) novos conhecimentos potencialmente significativos e 2) 
predisposição para aprender. Moran (2013) complementa, destacando que os principais elementos que podem instigar a aprendizagem são: motivação, inteligência, idade, percepção, memória, conhecimentos anteriores (prévios) e fatores sociais. Assim, a aprendizagem está envolvida em múltiplos fatores, que implicam mutuamente e que embora os possamos analisar em separado fazem parte de um todo que depende, quer na sua natureza, quer na sua qualidade, de uma série de condições internas e externas ao sujeito.

Procurou-se, ainda, verificar por quais razões os escolares sentiram-se motivados em modificar seus hábitos promotores de saúde. Através da categorização das respostas dos alunos, percebeu-se que $70 \%$ das motivações dos alunos do Grupo A estavam de uma maneira ou de outra relacionadas com as aulas ou com conceitos desenvolvidos na mesma, como se pode observar nos extratos a seguir, retirados das respostas dos alunos:

"[...] eu me interessei pelas aulas e até comecei a fazer caminhadas" (Aluno 1, Grupo A).

"Porque a aula era interessante e legal, aprendi a preocupar com o meu corpo e minha saúde" (Aluno 2, Grupo A).

"Aprendi que cuidar da saúde é muito importante. Decidi mudar meus hábitos" (Aluno 3, Grupo A).

Enquanto que apenas $22 \%$ das motivações dos alunos do Grupo B e $29 \%$ das do Grupo $C$ apontaram estar relacionadas com as aulas ou com conceitos desenvolvidos na mesma. Já a maioria dos escolares do Grupo B e C, 78\% e 71\% respectivamente, e $30 \%$ dos alunos do Grupo A demonstraram motivação relacionada apenas com a aparência física. Como nos extratos das respostas dos alunos:

“[...] mudei meus hábitos porque quero emagrecer" (Aluno 4, Grupo B).

"Quero perder peso" (Aluno 5, Grupo B).

"Não prestei muita atenção nas aulas, mas quero emagrecer" (Aluno 6, Grupo C). 
"Quero ficar em forma. Mas não fizemos muita coisa nas aulas" (Aluno 7, Grupo C).

Ao verificar as distinções das razões apontadas pelos alunos, procurou averiguar as diferenças entre os grupos. Constatando-se que houve diferenças estatisticamente significativas apenas entre os Grupos A e B $(p=0,003)$ e Grupos A e $C(p=0,009)$.

Para Medina (2004), a meta de todo sistema educativo é conseguir que os estudantes adquiram conhecimento que possam aplicar em diversas situações de sua vida cotidiana pessoal e profissional, ou seja, que este conhecimento tenha significado e sentido para eles. Aprender deve ser entendido como compreensão de significados relacionados a experiências anteriores, permitindo que os mesmos possam ser aplicados em novos contextos. Este tipo de aprendizagem, segundo Moreira (2011), é definida, por David Ausubel ${ }^{6}$, como aprendizagem significativa, correspondendo ao processo pelo qual uma nova informação se relaciona com um aspecto relevante da estrutura de conhecimento do aluno. Além disso, entende-se que a aprendizagem é significativa quando os estudantes conseguem "estabelecer relações substantivas e não-arbitrárias entre os conteúdos escolares e os conhecimentos previamente construídos por eles, num processo de articulação de novos significados" (BRASIL, 1997).

Mas, segundo Domingues (2006), ainda é considerada árdua, pelos docentes, a tarefa de concretizar, na prática, a organização dos conteúdos de acordo com os processos de aprendizagem significativa. "Muitas vezes, a proposta de organização curricular é permeada por concepções disciplinares ou de matérias que não se constroem a partir de situações e problemas da prática" (DOMINGUES, 2006, p.38). Corroborando essa afirmação, Deuner (2010) salienta que se o professor, mesmo trabalhando por aprendizagem por projetos na escola, ficar atrelado a grade curricular convencional/tradicional, os projetos tendem a ficarem sobrepostos ao currículo, tornando-se quase sempre uma atividade secundária e marginal. A

\footnotetext{
${ }^{6}$ David Ausubel foi professor Emérito da Universidade de Columbia, em Nova York. Dedicou-se sua carreira acadêmica à psicologia educacional. Elaborou a teoria da aprendizagem significativa, definida por um processo por meio do qual uma nova informação relaciona-se, de maneira substancial (não-literal) e não-arbitrária, a um aspecto relevante da estrutura de conhecimento do indivíduo (MOREIRA, 2011).
} 
prioridade, neste caso, continua sendo o cumprimento da grade curricular, com sua filosofia, seus objetivos, seus métodos, seus valores. Os projetos, se executados, precisam tentar se enquadrar à aula, cabendo ao professor fazer a adaptação para sua turma.

Como limitações do estudo, pode-se apontar o número reduzido de professores que fizeram parte dos projetos, suas características individuais, formação inicial, formação continuada e concepções sobre o processo ensinoaprendizagem, que podem interferir na metodologia aplicada pelo professor. Além disso, alguns aspectos que não puderam ser controlados na presente pesquisa, são fatores que podem afetar a percepção de motivação dos escolares, tais como: interesse pessoal, estado nutricional atual, fatores psicológicos e sociais. Apesar disso, o presente estudo de caso incorporou múltiplas fontes de dados, triangulação de técnicas e instrumentos que permitiu também minimizar tais limitações.

\section{CONSIDERAÇÕES FINAIS}

A partir das análises e discussões dos resultados do presente estudo, é possível inferir que os alunos e professores perceberam maior motivação e aprendizado quando desenvolvida uma proposta de aprendizagem por projetos, pela qual o aluno construiu seu conhecimento de forma colaborativa e o professor agiu como mediador da aprendizagem (Grupo A).

Já quando houve a centralidade do processo ensino-aprendizagem pelo professor (Grupo B e C), a percepção de motivação e aprendizado foi menor. Nesse sentido, um dos limites que podem ser encontrados no desenvolvimento de uma proposta de aprendizagem por projetos, quando desenvolvidos temas sobre a promoção da saúde, no ambiente escolar, é que os processos interativos proporcionados estão condicionados à mediação docente, pois, no momento da intervenção pedagógica, se não houver a compreensão que o aluno aprende no processo de produzir, de pesquisar e de criar relações que lhe impulsionam a contextualizar conceitos de saúde, que emergem durante o desenvolvimento do projeto, os conteúdos aprendidos terão pouco significado para os escolares. 
Por fim, pode-se referir que a aprendizagem por projetos, quando centrada em problematizações e desenvolvida com a participação ativa dos alunos na construção do conhecimento, pode influenciar de maneira decisiva na aprendizagem de conceitos relacionados a sua saúde, bem como prepará-los para a utilização de medidas práticas de promoção, proteção e recuperação da saúde ao seu alcance.

\section{PHILLIP VILANOVA ILHA}

Mestre em Educação em Ciências: Química da Vida e Saúde pela Universidade Federal de Santa Maria - UFSM. Doutorando em Educação em Ciências: Química da Vida e Saúde pela UFSM. Professor do Estado do Rio Grande do Sul.

\section{ANA PAULA SANTOS LIMA}

Mestre em Educação em Ciências pelo Programa de Pós-Graduação em Educação em Ciências: Química da Vida e Saúde pela Universidade Federal de Santa Maria UFSM. Doutoranda em Educação em Ciências: Química da Vida e Saúde na UFSM. Bolsista CAPES. Professora da rede municipal de Santa Maria/RS.

\section{DANIELA SASTRE ROSSI VISINTAINER}

Mestre em Educação em Ciências: Química da Vida e Saúde pela Universidade Federal de Santa Maria - UFSM. Doutoranda do Programa de Pós-Graduação de Educação em Ciências: Química da Vida e Saúde na UFSM.

\section{EDIANE MACHADO WOLLMANN}

Mestre em Educação em Ciências: Química da Vida e Saúde pela Universidade Federal de Santa Maria - UFSM. Docente da Carreira de Magistério do Ensino Básico, Técnico e Tecnológico no Instituto Federal Farroupilha - Câmpus Alegrete. Doutoranda no Programa de Pós Graduação em Educação em Ciências: Química da Vida e Saúde na UFSM.

\section{FÉLIX ALEXANDRE ANTUNES SOARES}

Doutor em Ciências Biológicas (Bioquímica) pela Universidade Federal do Rio Grande do Sul - UFGRS. Pós-Doutor em bioquímica toxicológica pela Universidade Federal de Santa Maria - UFSM e em biologia molecular pela Universidade de Leon (Espanha). Professor do Programa de Pós-Graduação de Educação em Ciências: Química da Vida e Saúde da UFSM.

\section{REFERÊNCIAS}

AMARAL, A. L. Conflito conteúdo/forma em pedagogias inovadoras: a pedagogia de projetos na implantação da escola plural. In: MARIN, A.; MONTEIRO, A.; SOUZA, M. I. M. (orgs.). Situações didáticas. Araraquara: JM Editora, 2003. p. 177-189. 
ARAÚJO, U. F. Temas Transversais e a Estratégia de Projetos. São Paulo:

Moderna, 2003, $111 \mathrm{p}$.

ASSIS, S. S et al.. Educação em saúde - proposta de utilização de um modelo no ensino de ciências. REMPEC - Ensino, Saúde e Ambiente, Niterói, v. 3, n. 2, 2010. Disponível em:

<http://www.ensinosaudeambiente.com.br/edicoes/volume\%203/texto10sheilasoares .pdf > Acesso em: 3 nov. 2014.

AUSUBEL, D. P.; NOVAK, J. D.; HANESIAN, H. Psicologia educacional. Rio de Janeiro: Interamericana. Tradução para o português do original Educational psychology: a cognitive view, 1980, 625 p.

BARDIN, L. Análise de conteúdo. São Paulo: Edições 70, 2011, 280 p.

BEHRENS, M. A. Paradigma da complexidade: metodologia de projetos, contratos didáticos e portifólios. Rio de Janeiro: Vozes, 2006, 136 p.

BRASIL. Lei 9.394 de 20 de dezembro de 1996. Estabelece as Diretrizes e Bases da educação Nacional. Diário Oficial da União, 1996.

BRASIL. Secretaria de Educação Básica. Orientações Curriculares para o Ensino Médio. SEB - Brasília: Ministério da Educação, 2006.

Secretaria de Educação Básica. Orientações Educacionais Complementares aos Parâmetros Curriculares Nacionais. SEB - Brasília: Ministério da Educação, 2002.

. Secretaria de Educação Básica. Parâmetros Curriculares Nacionais para o Ensino Médio. SEB - Brasília: Ministério da Educação, 2000.

. Secretaria de Ensino Fundamental. Parâmetros Curriculares Nacionais. Brasília: Ministério da Educação, 1997.

DEUNER, M. B. K. O desafio de desenvolver um projeto de aprendizagem com crianças não alfabetizadas. 2010. 39p. Trabalho de Conclusão de Curso (Graduação em Pedagogia) - Faculdade de Educação. Universidade Federal do Rio Grande do Sul, Porto Alegre.

CASALE, A. Aprendizagem baseada em problemas: desenvolvimento de competências para o ensino em engenharia. 2013. 162p. Tese (doutorado) - Escola de Engenharia de São Carlos. Universidade de São Paulo, São Paulo.

DONINGUES, S. G. O ensino-aprendizagem por projetos no Ensino Médio: Estudo crítico de um caso em implantação numa escola pública paulista. 2006. 154p.

Dissertação (mestrado) - Pontifícia Universidade Católica de São Paulo, São Paulo. 
FAGUNDES, L. C; SATO, L. S; MAÇADA, D. L. Aprendizes do futuro: as inovações começaram! Brasília: MEC, 1999, 95 p.

HELM, J. H; BENEKE, S. O Poder dos projetos: novas estratégias e soluções para a educação infantil. Porto Alegre: Artmed, 2005, 176 p.

HERNANDEZ, F.; VENTURA, M. A Organização do Currículo por Projetos de Trabalho: o conhecimento é um caleidoscópio. Porto Alegre: Artes Médicas, 1998, 200 p.

MEDINA, N. O. Avaliação do pensamento crítico em um cenário de escrita colaborativa. 2004. 100p. Tese (doutorado) - Pontifícia Universidade Católica de São Paulo, São Paulo.

MELLO, G. N.; DALLAN, M. C.; GRELLET, V. Projetos como alternativa de ensino e aprendizagem. In: MELLO G. N. Educação escolar brasileira: o que trouxemos do século XX? São Paulo: Artmed, 2004, p. 1-5.

MIOCH, R. Quando o ambiente de trabalho prejudica o desenvolvimento profissional do professor. In: MIOCH, R. Mudar para melhor: pequenos passos rumo ao êxito para todos. São Paulo: SE/APS, 1997, p. 24-31.

MORAN, J. Novas tecnologias e mediação pedagógica. 21. ed. Campinas: Papirus, 2013, $176 \mathrm{p}$.

MOREIRA, M. A. Teorias de aprendizagem. 2. ed. São Paulo: EPU, 2011, 242 p.

MOURA, D. G; BARBOSA, E. S. Trabalhando com projetos: planejamento e gestão de projetos educacionais. 4.ed. Rio de Janeiro: Vozes, 2009, 246 p.

NOGUEIRA, N. R. Pedagogia dos Projetos: etapas, papéis e atores. 2. ed. São Paulo: Editora Érica, 2006, 104 p.

PEREIRA, M. G et al. Aprender a escolher: promoção da saúde no contexto escolar. Psicologia: teoria, investigação e prática, Portugal, v. 5, n. 1, p. 147-158, 2000.

PRADO, M. Pedagogia de Projetos. In: BRASIL. Programa Salto para o Futuro. Gestão Escolar e Tecnologias, 2003, p. 1-14.

ROJO, M. R. Hacia uma didáctica crítica. Madrid: La Muralla S.A, 1997, 224 p.

VALADÃO, M. M. Saúde na Escola: um campo em busca de espaço na agenda intersetorial. 2004. 154p. Tese (doutorado) - Faculdade de Saúde Pública.

Universidade de São Paulo, São Paulo.

WHO. WHOQOL Measuring quality of life. Genebra: WHO, 1997. [acesso 04 nov 2014]. Disponível em <http://www.who.int/mental_health/media/68.pdf>. 
Atos de Pesquisa em Educação - ISSN 1809-0354

Blumenau, v. 10, n.1, p.280-303, jan./abr. 2015

DOI: http://dx.doi.org/10.7867/1809-0354.2015v10n1p280-303

304

YIN, R. K. Estudo de caso: planejamento e métodos. $2^{\mathrm{a}}$ ed. Porto Alegre: Bookman, 2001, 248 p. 